Author Accepted Manuscript

Accepted by Acta Materialia, 12 January 2018

\title{
Novel deformation-induced polymorphic crystallization and softening of Al-based amorphous alloys
}

H. W. Bi ${ }^{1}$, A. Inoue ${ }^{1-4}$, F. F. Han ${ }^{1}$, Y. Han ${ }^{1}$, F. L. Kong ${ }^{2}$, S. L. Zhu ${ }^{1}$, E. Shalaan ${ }^{3}$, F. Al-Marzouki ${ }^{3}$ \& A. L. Greer ${ }^{5}$

${ }^{1}$ School of Materials Science and Engineering, Tianjin University, Tianjin, 300072, China

${ }^{2}$ International Institute of Green Materials, Josai International University, Togane, 283-8555, Japan

${ }^{3}$ Department of Physics, King Abdulaziz University, Jeddah, 22254, Saudi Arabia

${ }^{4}$ National University of Science and Technology, MISiS, Moscow, 119049, Russia

${ }^{5}$ Department of Materials Science and Metallurgy, University of Cambridge, Cambridge, CB3 OFS, UK

Corresponding author:

A. Inoue

E-mail: ainouebmg@yahoo.co.jp

A.L. Greer

E-mail: alg13@cam.ac.uk 


\begin{abstract}
Melt-spun amorphous ribbons of $\mathrm{Al}_{90} \mathrm{Y}_{10}$ (at.\%) (90Al) and $\mathrm{Al}_{84} \mathrm{Y}_{8.5} \mathrm{Ni}_{4} \mathrm{Co}_{2} \mathrm{Pd}_{1} \mathrm{Fe}_{0.5}$ (84Al) are cold-rolled at near to liquid-nitrogen temperature or at room temperature, inducing partial crystallization to nanoscale fcc $\mathrm{Al}(\alpha-\mathrm{Al})$. The crystallization is characterized and contrasted with the distinct sequences of reactions on annealing 90Al and 84Al amorphous alloys. Rolling-induced crystallization leads to softening, opposite to the effect of nanocrystallization induced by annealing. The origins of the hardness changes are analyzed. The rolling induces novel polymorphic crystallization to $\alpha$-Al with extended solid solubility. This transformation, which occurs equally in $84 \mathrm{Al}$ and $90 \mathrm{Al}$, despite the much greater thermal stability of the former, allows the ribbons to retain good bending ductility, and delays the onset of embrittlement on subsequent annealing. Partial crystallization induced by cold-rolling is useful in avoiding the formation of compound phases associated with brittleness, and is a promising process for high-solute Al-based amorphous alloys to be further developed as structural materials.
\end{abstract}

Keywords: Amorphous alloy, Crystallization, Hardness, AP-FIM, HRTEM

\title{
1. Introduction
}

Aluminum-based amorphous alloys were first made in the system Al-Si-TM $(\mathrm{TM}=\mathrm{Fe}, \mathrm{Co}, \mathrm{Ni}, \mathrm{Cu})[1,2]$, then in Al-Ln-(Ni,Co) (Ln=lanthanide metal) and Al-TM- $(\mathrm{Ce}, \mathrm{Y})(\mathrm{TM}=\mathrm{Fe}, \mathrm{Co}, \mathrm{Ni})$ ternary alloys $[3,4]$, and Al-Y-Ni-Co quaternary alloys [5]. Amorphous Al-Ln-TM alloys show tensile strengths above $980 \mathrm{MPa}$ [3], with a maximum of $>1500 \mathrm{MPa}$ for Al-Y-Ni-Co-Sc [6]. On heating Al-based amorphous [am] alloys, in some cases, there is a glass transition followed by a supercooled-liquid (SL) region before crystallization which proceeds in stages. Above $~ 88$ at.\% $\mathrm{Al}$, there is no detectable glass transition, and crystallization starts with the formation of fcc-Al $(\alpha-\mathrm{Al})$ nanocrystals: $\quad[\mathrm{am}] \rightarrow[\mathrm{am}+\alpha-\mathrm{Al}] \rightarrow[\alpha-\mathrm{Al}+$ compounds]. With $85-88$ at.\% $\mathrm{Al}$, the sequence is $[\mathrm{am}] \rightarrow \mathrm{SL} \rightarrow[\mathrm{am}+\alpha-\mathrm{Al}] \rightarrow$ 
$[\alpha-\mathrm{Al}+$ compounds $] . \quad$ Below 84 at. $\% \mathrm{Al}$, the sequence is: $\quad[\mathrm{am}] \rightarrow \mathrm{SL} \rightarrow[\alpha-\mathrm{Al}+$ compounds] [7-10]. As recently shown [11] for the multicomponent alloy $\mathrm{Al}_{84} \mathrm{Y}_{9} \mathrm{Ni}_{4}(\mathrm{Co}, \mathrm{Fe}, \mathrm{Pd})_{3}($ at. $\%)$, the sequence is: $[\mathrm{am}] \rightarrow \mathrm{SL} \rightarrow[\mathrm{am}+\alpha-\mathrm{Al}+$ cubic $\left.\mathrm{Al}_{x} \mathrm{M}_{y}(\mathrm{M}=\mathrm{Y}, \mathrm{Fe}, \mathrm{Co}, \mathrm{Ni}, \mathrm{Pd})\right] \rightarrow[\mathrm{am}+\alpha-\mathrm{Al}] \rightarrow\left[\alpha-\mathrm{Al}+\mathrm{Al}_{3} \mathrm{Y}+\mathrm{Al} 9(\mathrm{Ni}, \mathrm{Co})_{2}+\right.$ unknown phase]. Here, the key observation is the novel reverse transformation [am $\left.+\alpha-\mathrm{Al}+\mathrm{Al}_{x} \mathrm{M}_{y}\right] \rightarrow[\mathrm{am}+\alpha-\mathrm{Al}]$, in which the volume fraction of amorphous phase increases on heating. The applications of Al-based amorphous alloys to date are mainly due to the exploitation of [am $+\alpha-\mathrm{Al}]$ mixtures with high strength and good warm formability. The reverse transformation is of interest in expanding the composition and temperature ranges of the $[\mathrm{am}+\alpha-\mathrm{Al}]$ mixture. Importantly, the possibilities for achieving this phase mixture are extended in the present work.

Cold-rolling of Al-based amorphous alloys with 8-15 at.\% solute causes the precipitation of $\alpha$-Al nanocrystals in shear bands, and leads to a decrease in the onset temperature of crystallization on heating $[12,13]$. However, there has been no systematic study of compositional effects on these phenomena. The present work explores structural stability and mechanical properties for two Al-based amorphous alloys subjected to cold-rolling. The alloys are chosen from composition ranges with very different thermal stabilities. The $\mathrm{Al}_{90} \mathrm{Y}_{10}$ alloy [14] shows the onset of crystallization at $485 \mathrm{~K}$. The $\mathrm{Al}_{84} \mathrm{Y}_{8.5} \mathrm{Ni}_{4} \mathrm{Co}_{2} \mathrm{Pd}_{1} \mathrm{Fe}_{0.5}$ alloy is similar to the $\mathrm{Al}_{84} \mathrm{Y}_{9} \mathrm{Ni}_{4}(\mathrm{Co}, \mathrm{Fe}, \mathrm{Pd})_{3}$ alloys that show crystallization onset at $\sim 576 \mathrm{~K}$ [11]. Upon cold-rolling, melt-spun amorphous ribbons of these alloys show a type of nanocrystallization not previously reported. Contrary to the hardening effect of thermally induced crystallization, the mechanically induced crystallization is associated with softening. We characterize the changes in structure, crystallization behavior, hardness and plasticity induced by cold-rolling, and explore the mechanisms of hardening and softening.

\section{Experimental methods}

The two alloys have nominal compositions (in at.\%) of $\mathrm{Al}_{90} \mathrm{Y}_{10}(90 \mathrm{Al})$ and 
$\mathrm{Al}_{84} \mathrm{Y}_{8.5} \mathrm{Ni}_{4} \mathrm{Co}_{2} \mathrm{Pd}_{1} \mathrm{Fe}_{0.5}$ (84Al). Ingots were prepared by arc-melting mixtures of elemental metals with purities above 99.8 wt.\% under an argon atmosphere. Alloy ribbons with a thickness of $35-45 \mu \mathrm{m}$ and a width of $1.2 \mathrm{~mm}$ were prepared by melt spinning under an argon atmosphere. The structure of the as-spun ribbons was confirmed to be amorphous by X-ray diffractometry (XRD) (Suppl. Info., Fig. S1).

For cold-rolling, the ribbon samples were sandwiched between two type-304 stainless-steel plates, each with an initial thickness of $2 \mathrm{~mm}$. The sandwich structures were passed through a twin-roller machine to obtain a thickness reduction of $\sim 5 \%$ in each pass. Several passes were used to obtain ribbons with total thickness reductions in the range $20-85 \%$. Rolling was conducted mostly close to liquid-nitrogen temperature (LNT, $77 \mathrm{~K}$ ); for this, the sandwich structure was immersed in liquid nitrogen for 10 min before being taken out and immediately rolled. In some cases, for comparison, rolling was conducted at room temperature (RT). The initial Vickers hardness of the stainless steel sheet is 270 and this ultimately rises to $\sim 600$ as a result of the rolling.

The structure of the cold-rolled ribbons was examined by XRD, scanning electron microscopy (SEM), standard transmission electron microscopy (TEM) and high-resolution TEM (HRTEM) including nanobeam diffraction. The spatial distribution of the component elements was examined by atom-probe field-ion microscopy (APFIM, Cameca LEAP 3000HR time-of-flight atom probe). The samples for this were prepared by grinding ribbons down to square rods of about 20 $\mu \mathrm{m} \times 20 \mu \mathrm{m} \times 5 \mathrm{~mm}$ and then polishing by ion milling. The field-ion microscopy (FIM) images were obtained using $\mathrm{Ne}$ as the imaging gas at $25-40 \mathrm{~K}$. The atom probe analysis was performed at $35 \mathrm{~K}$ under a vacuum of $\sim 1 \times 10^{-8} \mathrm{~Pa}$ with a pulse fraction $\left(V_{\mathrm{p}} / V_{\mathrm{dc}}\right)$ of 0.15 and a pulse repetition rate of $100 \mathrm{~Hz}$.

The thermal stability of the as-spun and cold-rolled ribbons was examined by differential scanning calorimetry (DSC) at a heating rate of $0.67 \mathrm{~K} / \mathrm{s}$. Microhardness

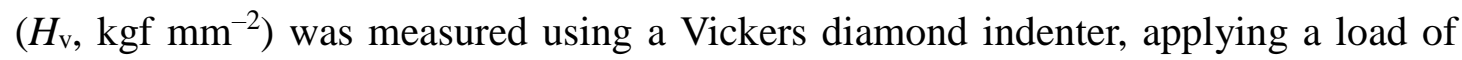
$0.49 \mathrm{~N}$ and a dwell time of $10 \mathrm{~s}$. Bending ductility was evaluated by a simple bend test. Slip markings around Vickers microhardness indents and on the surface of 
bend-test samples were examined by optical microscopy (OM) and SEM.

\section{Results}

\subsection{Structural effects of cold-rolling}

The effects of cold-rolling were characterized using TEM and HRTEM (Fig. 1). After rolling at LNT, both $90 \mathrm{Al}$ and $84 \mathrm{Al}$ consist of $\alpha$-Al crystallites in an amorphous matrix. In $90 \mathrm{Al}$, the crystallite diameter is $2-25 \mathrm{~nm}$ and in $84 \mathrm{Al}$ it is $2-12 \mathrm{~nm}$. For 90Al, the nanostructure induced by cold-rolling appears nearly the same as that induced by annealing [15]. For 84Al the phase mixture is different; in particular cold-rolling avoids the $\mathrm{Al}_{x} \mathrm{M}_{y}$ compound formed on heating [11].

\section{Figure 1 near here}

Based on the HRTEM images, the lattice parameter of the $\alpha-\mathrm{Al}$ is $\sim 0.407 \mathrm{~nm}$ in both $90 \mathrm{Al}$ and $84 \mathrm{Al}$ after rolling at LNT; this is significantly larger than the value of $0.405 \mathrm{~nm}$ for pure $\alpha-\mathrm{Al}$. The difference in the lattice parameters suggests that the cold-rolling-induced $\alpha$-Al phase includes solutes, in particular $\mathrm{Y}$ with much larger atomic size. The lattice parameter of $\alpha-\mathrm{Al}$ in cold-rolled $90 \mathrm{Al}$ and $84 \mathrm{Al}$ is also larger than those $(0.405-0.406 \mathrm{~nm})$ for $\alpha-\mathrm{Al}$ obtained in similar alloys upon annealing $[11,16]$. Although difficult to quantify from the lattice parameter measurements, it seems that $\alpha$-Al induced by cold-rolling contains more solute $\mathrm{Y}$ than when induced by annealing.

TEM images of cold-rolled 90Al (Fig. 1a) reveal elongated regions (arrowed), suggesting that deformation occurs inhomogeneously through shear bands. The precipitation density of nanoscale $\alpha-\mathrm{Al}$ appears higher in the bands, reminiscent of shear-deformation-induced precipitation previously reported for 90Al $[17,18]$ and 92Al [19] amorphous alloys. In cold-rolled 84Al, in contrast, the micrograph (Fig. 1d) shows no evidence for shear bands, nor for heterogeneity of the precipitation density of $\alpha$-Al. Despite higher solute content, $84 \mathrm{Al}$ shows deformation that is more 
homogeneous than in 90Al.

\section{Figure 2 near here}

APFIM analysis was applied to $84 \mathrm{Al}$ after rolling at LNT to $R=86 \%$. The distribution profiles of the elements at a spot on the FIM tip as it is eroded by $150 \mathrm{~nm}$ (Fig. 2) show no significant variation with depth. This distance is much longer than the diameter $(2-12 \mathrm{~nm})$ of the $\alpha-\mathrm{Al}$ crystallites and the spacing between them, and thus any solute partitioning associated with the precipitation should be detected. There appears to be no significant solute partitioning between the $\alpha$-Al and amorphous phases, and no segregation or accumulation/depletion of solute at the $\alpha-\mathrm{Al} /$ amorphous interfaces. That the formation of the $\alpha-\mathrm{Al}$ solid solution is thus polymorphic, is reinforced by the distribution maps for the elements in the tip (Fig. 3). These results sharply contrast with the effects of annealing-induced crystallization which is associated with solute partitioning. To distinguish, we henceforth use $\alpha-\mathrm{Al}$ to refer to the thermally induced phase, and SSSS-Al to refer to the supersaturated solid solution induced by cold-rolling.

\section{Figure 3 near here}

The TEM, HRTEM and AP-FIM studies have been used to characterize the structural changes induced by heaviest deformation (cold-rolling to reductions in thickness $R=75 \%-86 \%$ ). The trends in structure with progressively increasing $R$ are more readily followed using XRD and DSC. In XRD, the amorphous haloes for both $90 \mathrm{Al}$ and $84 \mathrm{Al}$ show only slight, progressive changes (Fig. S1) on rolling at LNT (77 K) up to $80 \%$ reduction in thickness $(R=80 \%)$. The Bragg angle of the halo maximum decreases slightly and the halo width increases, suggesting that the deformation leads to a decrease in the density of the samples and to an increase in their heterogeneity. The (200) reflection of fcc-Al becomes detectable in heavily rolled 90Al. More importantly, however, at around the same Bragg angle (in the 
boxed areas in Fig. S1a,b), the XRD patterns for both 90Al and 84Al show a broad shoulder on the side of the amorphous halo. This is consistent with the cold-rolling generating a fine dispersion of SSSS-Al nanocrystals. Similar effects have been seen in mechanical milling [20] and mechanical alloying [21] of $\mathrm{Al}$ alloys in which mixed structures consisting of amorphous + nanoscale crystalline phases are obtained. As in the present work, these structures can be observed in high-resolution TEM images, yet there are no distinct crystalline peaks in the corresponding XRD patterns.

\section{Figure 4 near here}

DSC on heating shows no glass transition for as-spun ribbons of 90Al (Fig. 4a); for $84 \mathrm{Al}$ there is a clear glass transition followed by a very limited temperature range of supercooled liquid (Fig. 4b). For both alloys, crystallization proceeds in stages, the DSC traces showing three exothermic peaks. XRD (Fig. 5) of samples annealed at temperatures within the first DSC peak permits identification of the phase mixtures after first-stage crystallization. For the 90Al amorphous alloy the mixture is [am + $\alpha-\mathrm{Al}]$, as expected from earlier studies of this composition [15,22] and related compositions $[9,11,23]$. One earlier study of this amorphous alloy reported that a tetragonal phase appears after the precipitation of $\alpha-\mathrm{Al}$ at the same temperature [14], but there is no evidence for this in the present work.

\section{Figure 5 near here}

For 84Al, the phase mixture generated in the first peak is [am $+\alpha-\mathrm{Al}]$ plus a complex cubic intermetallic $\mathrm{Al}_{x} \mathrm{M}_{y}$, (M represents a mixture of the solutes in the alloy), again consistent with earlier studies $[11,23,24]$. The first and second crystallization peaks for as-spun $90 \mathrm{Al}$ have onset temperatures $T_{\mathrm{x} 1}=485 \mathrm{~K}$ and $T_{\mathrm{x} 2}=542 \mathrm{~K}$ that are both well below the $T_{\mathrm{x} 1}$ value $(584 \mathrm{~K})$ for as-spun $84 \mathrm{Al}$. Thus, as would be expected from its higher solute content, the $84 \mathrm{Al}$ alloy is significantly more stable against thermally induced crystallization. 
After rolling at LNT, DSC shows a trend towards smaller crystallization enthalpies, and we use this to estimate the degree of crystallization induced by the mechanical treatment. We characterize the rolled samples in terms of the fractional reduction $F$ in the total enthalpy of transformation (i.e. the total heat released in all three peaks). The complex sequence of reactions precludes a simple linear relationship between total heat released and total volume fraction crystallized. Nevertheless, we take the percentage reduction in heat released as a qualitative indicator of the volume fraction crystallized, suitable for semi-quantitative comparisons. For both $90 \mathrm{Al}$ and $84 \mathrm{Al}$, the main effect of cold-rolling is a reduction in the area of the first DSC peak (Fig. 4a,b). The second DSC peak is also affected (more obviously for $84 \mathrm{Al}$ than for $90 \mathrm{Al}$ ), and the peak temperatures show systematic changes as $R$ increases (Fig. 4c).

We do not attempt a detailed interpretation of these effects. From the TEM, HRTEM and AP-FIM, we note that cold-rolling induces partial crystallization to SSSS-Al. The polymorphic nature of the transformation should leave the composition of the residual amorphous phase unchanged. We therefore expect that the rolling-induced decrease in the area of the first peak (for both $90 \mathrm{Al}$ and $84 \mathrm{Al}$ ) is simply because there is less amorphous phase left to transform.

As a function of reduction in thickness $R$, the reduction $F$ in the total enthalpy of transformation can be nearly as high as $30 \%$ (Fig. 4d). The two amorphous alloys 90Al and 84Al show similar (largely overlapping) trends of $F$ vs $R$. For each alloy, the effects of rolling at RT are somewhat greater than for rolling at LNT.

\section{Figure 6 near here}

\subsection{Hardness changes}

As a result of cold-rolling, the Vickers microhardness $\left(H_{\mathrm{v}}\right)$ of both $90 \mathrm{Al}$ and $84 \mathrm{Al}$ decreases (Fig. 6a,b). As-spun 90Al has $H_{\mathrm{v}}=220 \pm 4$, which decreases to $157 \pm 3.5$ after thickness reduction of $80 \%$ at RT, and to $149 \pm 3.5$ after thickness reduction of 
$75 \%$ at LNT, total decreases of $28-33 \%$. As-spun $84 \mathrm{Al}$ has a hardness of $415 \pm 4$, which decreases to $275 \pm 5$ after $R=80 \%$ at RT or $R=72 \%$ at LNT, a total decrease of 34\%. The softening effect is slightly greater for rolling at LNT.

A reduction in hardness associated with increasing fraction of fcc-Al in Al-based amorphous alloys has not been reported before, and contrasts with reported hardening associated with annealing-induced crystallization. We can compare the mechanically induced crystallization of $84 \mathrm{Al}$ with thermally induced crystallization of a similar 84 at.\% $\mathrm{Al}$ alloy $\left(\mathrm{Al}_{84} \mathrm{Y}_{9} \mathrm{Ni}_{4} \mathrm{Co}_{1.5} \mathrm{Pd}_{1} \mathrm{Fe}_{0.5}\right)$ in earlier work [11]. On annealing the latter to obtain $\sim 50 \%$ volume fraction of $\alpha$-Al nanocrystals, $H_{\mathrm{v}}=$ $595 \pm 10$ (an increase of 43\%) [11]; this contrasts with the mechanically induced 34\% reduction noted above, associated with a lower volume fraction $(\sim 25 \%$, if scaled with F) of SSSS-Al nanocrystals.

Annealing of rolled samples below the temperature of crystallization onset can give partial recovery towards higher $H_{\mathrm{v}}$ (Fig. 7, in which data for as-spun alloys are included for comparison). On annealing at $450 \mathrm{~K}\left(T_{\mathrm{x} 1}-35 \mathrm{~K}\right)$, as-spun $90 \mathrm{Al}$ (Fig. 7a) shows a gradual increase in $H_{\mathrm{v}}$ until a rise from $\sim 210$ to $\sim 220$ at $\sim 2500 \mathrm{~s}$, attributed to crystallization onset: $[\mathrm{am}] \rightarrow[\mathrm{am}+\alpha-\mathrm{Al}]$. A ribbon rolled at LNT to $R$ $=37 \%$ has, as expected, a lower hardness, and annealing appears to have no systematic effect on this. In contrast, a ribbon rolled at LNT to $R=71 \%$ shows a sharp initial rise over $300 \mathrm{~s}$ from $\sim 163$ to $\sim 187$, a value similar to the hardness for the $R=37 \%$ ribbon, and representing a $42 \%$ recovery towards the $220 \pm 4$ value for the as-spun alloy. As-spun 84Al (Fig. 7b) also shows little change in hardness on annealing at $525 \mathrm{~K}\left(T_{\mathrm{x} 1}-60 \mathrm{~K}\right)$ and there is no detectable crystallization. A ribbon rolled at LNT to $R=37 \%$ has, again, a lower hardness that is not systematically affected by annealing. A ribbon rolled to $R=71 \%$ shows slow hardening over $3000 \mathrm{~s}$ from $\sim 280$ to $\sim 317$, a $27 \%$ recovery towards the $415 \pm 4$ value for the as-spun alloy.

\section{Figure 7 near here}

The annealing-induced increases in hardness of the rolled alloys can be 
considered relative to the hardness of the as-spun amorphous alloys. The increase is $13 \%$ for $90 \mathrm{Al}$ and $11 \%$ for $84 \mathrm{Al}$, values similar to the degree of softening reported in an amorphous alloy heavily deformed to induce profuse shear-banding but no detectable crystallization [25]. For each alloy, we therefore attribute the annealing-induced recovery of hardness to structural relaxation of the deformed amorphous matrix. For ribbons of both $90 \mathrm{Al}$ and $84 \mathrm{Al}$ rolled at LNT to the lesser $R$ $=37 \%$, there is no perceptible effect of subsequent annealing (Fig. 7a,b), so the reversible softening of the matrix seems to be prominent only in the later stages of rolling. Of the ultimate hardness reduction induced by rolling at LNT, it seems that for $90 \mathrm{Al} \sim 77 \%$ can be attributed to softening of the amorphous phase $\sim 23 \%$ to formation of $\alpha$-Al nanocrystals; for $84 \mathrm{Al}$, these fractions are $\sim 58 \%$ and $\sim 42 \%$ respectively.

Noting that the annealing-induced partial recovery of hardness (Fig. 7) is seen only at larger $R$, we consider again the hardness reductions in Fig. 6a,b, and we can attribute the divergence of the LNT and RT data at larger $R$ to a greater softening of the amorphous matrix on rolling at LNT. Greater softening can be expected because the steady-state amorphous state induced by deformation is determined by the balance of damage and relaxation (i.e. repair) rates; at lower deformation temperature, relaxation is slower and higher-energy states (softer) states are attained [26]. The data in Fig. 6a,b suggest acceleration of hardness reduction at larger $R$; this is attributed to softening of the amorphous matrix and to acceleration in the crystallization as rolling is continued (Fig. 4d).

The data in Fig. 4d and Fig. 6a,b can be used to show how the microhardness of the cold-rolled alloys decreases as a function of $F$ (Fig. 6c). The microhardness is represented as a percentage of the initial $H_{\mathrm{v}}$ of the as-spun $90 \mathrm{Al}$ or $84 \mathrm{Al}$ ribbons. As a result of rolling at RT, the relative hardness decreases similarly for $90 \mathrm{Al}$ and $84 \mathrm{Al}$, and roughly linearly with increasing $F$. For rolling at LNT, the hardness is lower for a given value of $F$, an effect attributed to the deformation-induced softening of the amorphous phase discussed in connection with Fig. 7. On the relative hardness scale in Fig. 6c, the annealing-induced recovery seen for the $R=71 \%$ ribbons in Fig. 7a,b 
would be $11 \%$ and $9 \%$ respectively, enough to bring the LNT and RT data for $90 \mathrm{Al}$ and $84 \mathrm{Al}$ in Fig. 6c into rough co-alignment. We conclude that the reduction in hardness attributable to the development of a crystalline volume fraction is similar for $90 \mathrm{Al}$ and $84 \mathrm{Al}$.

The annealing-induced recovery of hardness (Fig. 7) has been attributed to structural relaxation of the residual amorphous matrix. Another possible contribution to the effect could be solute redistribution between the SSSS-Al nanocrystals and the matrix; as the solutes diffuse into the matrix overall hardening could be expected. However, the variation of relative hardness with volume fraction, as noted above, is similar for $90 \mathrm{Al}$ and $84 \mathrm{Al}$ after the recovery is taken into account. This argues against solute redistribution, and in any case if the redistribution were significant we could expect overall hardening (i.e. evolution to relative hardnesses exceeding $100 \%)$.

\subsection{Plasticity of cold-rolled ribbons}

The plasticity of as-spun and cold-rolled ribbons was assessed by a simple bend test. After rolling at LNT, ribbons of 84Al retain good bending ductility (Fig. 8a), even though they consist of an [am + SSSS-Al] mixture. The same alloy annealed to obtain a $\left[\mathrm{am}+\alpha-\mathrm{Al}+\mathrm{Al}_{x} \mathrm{M}_{y}\right]$ mixture, in contrast, is extremely brittle. Figures $8 \mathrm{~b}$ and $8 \mathrm{c}$ show the ribbon surfaces in the bent region for as-spun and for LNT-rolled samples of 84Al. In the latter case, the density of shear bands is higher and the step height at each band is smaller, indicating more homogeneous bending deformation after rolling.

\section{Figure 8 near here}

The bending ductility was also assessed for LNT-rolled samples that were later annealed (as in Fig. 7). On annealing up to $3 \mathrm{ks}$, the ribbons of 90Al, both as-spun and cold-rolled, retained bending ductility (Fig. 7a). For 84Al (Fig. 7b), as-spun 
ribbons embrittled after $\sim 500 \mathrm{~s}$ and cold-rolled ribbons embrittled after $\sim 1300 \mathrm{~s}$. Cold-rolling thus delays the onset of embrittlement.

Table 1 summarizes the changes in the structure and bending ductility of $90 \mathrm{Al}$ and $84 \mathrm{Al}$ as a result of low-temperature isothermal annealing, heating to just above $T_{\mathrm{x} 1}$ for $600 \mathrm{~s}$, and cold-rolling. The [am + SSSS-Al] mixture can be obtained for the 84Al alloy only by cold-rolling, showing the potential to achieve non-equilibrium microstructures with attractive properties.

\section{Table 1 near here}

\section{Discussion}

\subsection{Comparison of thermally and mechanically induced crystallization}

The key finding is that the fcc-Al phase induced by cold-rolling is highly supersaturated and appears to have the same composition as the amorphous phase from which it forms. The crystallization must be polymorphic, with no partitioning of solute between the phases, and no segregation or accumulation/depletion of solute at the interface between the phases. This is directly shown for $84 \mathrm{Al}$ by the APFIM results (Figs 2 and 3). From the lattice parameter of the fcc-Al formed in the two alloys by cold-rolling (from HRTEM images, Fig. 1), and from qualitatively similar trends in crystallization (assumed from $F$ in Fig. 4d) and softening (Fig. 6), it is inferred that the mechanically induced crystallization in $90 \mathrm{Al}$ is likely also to be polymorphic.

On annealing, the atomic mobility that permits crystallization also permits solute partitioning; thus polymorphic crystallization to an elemental solid solution is improbable at least. Early reports of such crystallization [27] were for heating in-situ in TEM, and appear to be a specific effect not confirmed by studies of samples annealed before thin-foil preparation. We expect that thermally induced crystallization is polymorphic only when the amorphous alloy has the composition of a stoichiometric compound to which it is directly able to transform [28]. 
Polymorphic crystallization to a solid solution may, however, be possible for high-entropy alloys, and may be important in imparting high resistance to irradiation damage [29].

Mechanically induced crystallization of amorphous alloys has been widely studied, as reviewed in refs $[17,30]$. For amorphous $\mathrm{Al}_{90} \mathrm{Fe}_{5} \mathrm{Gd}_{5}, \alpha$-Al nanocrystals have been formed in bent ribbons [17]. Such nanocrystals appeared similar to those formed on annealing and, in particular, showed similar solute diffusion profiles around them [31]. The present work shows a contrasting case in which the mechanically induced nanocrystals have formed polymorphically. Nanocrystal formation is likely to be only at shear bands in $\mathrm{Al}_{90} \mathrm{Fe}_{5} \mathrm{Gd}_{5}$, but more generally throughout the more severely deformed samples in the present work. In shear bands, the very high mobility may permit solute partitioning that is not possible in the bulk. Amorphous $\mathrm{Al}_{90} \mathrm{Fe}_{5} \mathrm{Gd}_{5}$ can be distinguished from the alloys in the present work by its lower lanthanide content and much lower thermal stability $\left(T_{\mathrm{x} 1}=423 \mathrm{~K}\right)$. Bending of the $\mathrm{Al}_{90} \mathrm{Fe}_{5} \mathrm{Gd}_{5}$ ribbons was at RT (not LNT), and together with the low stability, this also may facilitate the development of solute diffusion profiles.

There can be significant local heating at shear bands during deformation. Nevertheless, it is concluded in most cases $[17,30]$ that crystallization within shear bands is made possible not by local heating, but by enhanced mobility directly induced by the shear. This conclusion appears valid in the present work, as the extent of crystallization induced by cold-rolling (Fig. 4d) appears to be not greatly affected by the temperature (LNT or RT) at which the rolling is conducted.

We propose that the polymorphic crystallization occurs with rearrangement of the short-range order and without any long-range transport, even on the nanometer scale of the crystallite diameter. This mechanically induced transformation traps all the solute in the SSSS-Al and provides an attractive route to achieving high degrees of supersaturation for many solutes without the need for extreme processing of the kind required to achieve solute trapping in solidification of liquid metallic alloys [32].

That mechanically induced crystallization of an Al-based amorphous alloy might be polymorphic was suggested by TEM observations and molecular-dynamics 
simulations of structural changes in the particular circumstances near a fatigue crack under cyclic loading $[33,34]$. That work suggested that accumulation of non-affine displacements under cyclic loading, rather than shear under monotonic loading, would lead to crystallization [34]. The present work shows that gross shear (plastic deformation by rolling) can also induce polymorphic crystallization. Both the work on cyclic loading $[33,34]$ and the present work emphasize the differences between thermally and mechanically induced crystallization highlighted by the contrasting behavior of the $90 \mathrm{Al}$ and $84 \mathrm{Al}$ amorphous alloys.

The 84Al alloy has a much higher thermal stability than 90Al, and its polymorphic crystallization to SSSS-Al should be restricted by its higher solute content. It is remarkable, then, that its stability against mechanically induced crystallization is only equal to that of $90 \mathrm{Al}$; why is $84 \mathrm{Al}$ so susceptible to mechanically induced crystallization? Guidance may be found from systematic studies (reviewed in ref. [35]) of different compositions in the model binary amorphous system $\mathrm{Cu}-\mathrm{Zr}$. On loading at $\mathrm{RT}$ in the elastic regime (at $90 \%$ of $\sigma_{\mathrm{y}}$ ), the samples undergo creep. In the range studied, a composition close to $\mathrm{Cu}_{65} \mathrm{Zr}_{35}$ is the most closely packed with the highest $\sigma_{\mathrm{y}}[35,36]$, and has the highest resistance to crystallization on annealing [37]. Yet this $\mathrm{Cu}_{65} \mathrm{Zr}_{35}$ amorphous alloy shows the most creep on elastostatic loading. The most stable, ordered amorphous alloy seems (under mechanical loading) to have the greatest capacity for generation of disorder and for increase in mobility [35]. Under elastostatic loading, the increase in mobility leads to creep, but it could equally facilitate crystallization [38]. These effects in the nominally elastic regime may equally apply in the plastic regime: a more ordered (thermally) stable amorphous alloy is more disrupted by mechanical deformation.

\section{Figure 9 near here}

A schematic thermodynamic description of crystallization in 84Al (Fig. 9) treats the system as binary, with all solutes considered together. The free energies of the $\alpha-\mathrm{Al}$ and $\mathrm{Al}_{x} \mathrm{M}_{y}$ phases are shown fixed, and relative to them the free energy of the 
solid amorphous alloy or supercooled liquid is shown for three temperatures. The free-energy minimum for $\alpha-\mathrm{Al}$ is shown rather broad, considering that the solubility limit may be high for the mixture of solutes with compensating sizes (Y larger, and all the other species smaller, than the solvent $\mathrm{Al}$ ). On annealing at crystallization onset $(584 \mathrm{~K})$, the amorphous alloy can lower its free energy (arrow 1 in this figure) by undergoing eutectic crystallization to $\alpha-\mathrm{Al}$ and $\mathrm{Al}_{x} \mathrm{M}_{y}$. At this temperature, polymorphic crystallization to $\alpha$-Al would not be possible thermodynamically (the free energy would rise) or kinetically (partitioning would occur). At RT or LNT, however, the driving force for crystallization is much greater, and polymorphic crystallization to $\alpha$-Al (arrow 2) is possible. Furthermore, solute transport is inhibited, so the formation of the $\mathrm{Al}_{x} \mathrm{M}_{y}$ compound, with composition different from that of the amorphous alloy, becomes impossible. Suppression of compound formation is important to avoid embrittlement on annealing.

There is current interest in rejuvenation of amorphous alloys by mechanical, and other, treatments [26]. It is not clear what limits the degree of rejuvenation that can be achieved, and one possibility is that a limit could be set by the onset of crystallization (most likely polymorphic). Such a mechanism is suggested by the current results.

\subsection{Hardening and softening mechanisms}

Cold-rolling causes the hardness of amorphous alloys to decrease through the disordering effects of increased free volume and local sheared regions. Table S1 (Suppl. Info.) summarizes changes in hardness of several amorphous alloys. On cold-rolling to $R=33-97 \%$, almost all the alloys show $H_{\mathrm{v}}$ reduced by $2-15 \%$, much smaller than the reductions of up to $32-34 \%$ for the cold-rolled alloys in the present work. The larger reductions in $H_{\mathrm{v}}$ can be attributed to partial crystallization of the cold-rolled alloys.

There has been much work on Al-based amorphous alloys and their crystallization. Nanophase composites, consisting of a dispersion of $\alpha$-Al 
nanocrystals in an amorphous matrix [16,39], can be obtained by quenching the liquid at the margins of glass formation, or by annealing fully amorphous material. The crystallites have a lower solute content than the matrix [40]. The composites are of interest because they combine significant plasticity with exceptionally high tensile yield stress $\sigma_{\mathrm{y}}$. At RT, $\sigma_{\mathrm{y}}$ can reach 1.5 times that of the corresponding fully amorphous alloy and $\sim 3$ times that of a conventional precipitation-hardened Al alloy [41]; at $300^{\circ} \mathrm{C} \sigma_{\mathrm{y}}$ can reach $1 \mathrm{GPa}, \sim 20$ times that of the best conventional alloys at the same temperature.

The mechanisms of hardening associated with partial crystallization remain uncertain. The $\alpha-\mathrm{Al}$ nanocrystals are so small as to be dislocation-free; they are usually considered to be hard, blocking the propagation of shear bands in the amorphous matrix or more generally hindering viscous flow $[42,43]$. On annealing, growth of the nanocrystals rejects solutes into the amorphous matrix, and Al-based amorphous alloys with higher solute content are harder. The hardening of the nanophase composites was therefore attributed to the solute enrichment of the matrix [44], though it was considered that the $\alpha$-Al nanocrystals would themselves be hard [45]. The hardening of 84-86 at.\% $\mathrm{Al}$ alloys (similar to $84 \mathrm{Al}$ in the present work) on annealing confirms that the solute content of the residual amorphous matrix is important [11].

The hardening is difficult to interpret because partial crystallization to $\alpha-\mathrm{Al}$ can involve both structural and compositional changes. The present results show that similar $[\mathrm{am}+\alpha-\mathrm{Al}]$ mixtures can be achieved with or without solute partitioning. The ability to compare these provides a novel opportunity to separate structural and compositional effects.

That the formation of SSSS-Al nanocrystals without solute partitioning leads to softening rather than hardening (Fig. 6) shows that the nanocrystals must be softer than the amorphous phase, not harder as previously generally assumed. In work on annealing-induced nanocrystallization and hardening, it had already been noted, however, that the nanocrystals have a ductilizing effect, since the nanophase composites showed more plasticity than single-phase Al-based amorphous alloys with 
the same composition as the residual amorphous matrix in the composites [44]. Clearly, ductilizing can be expected if the nanocrystals are softer than the matrix.

Since the nanocrystals are so small as to be dislocation-free, the finding that they are soft suggests that dislocation generation and annihilation must be easy at the crystal-amorphous interface. The absence of any solute enrichment, and defective configurations, at the fcc-Al/amorphous interface may be helpful. The deformation-induced softening also implies the lack of any appreciable work-hardening. This is significantly different from the general work-hardening behavior of severely plastically deformed crystalline and nanocrystalline alloys $[46,47]$.

The data in Fig. 6c, when deformation-induced matrix softening is discounted, suggest that with $F \approx 25 \%$, the hardness is $\sim 70 \%$ of the value for the as-spun amorphous alloy. Assuming that, roughly, the hardness obeys a rule of mixtures, this implies that the effective hardness of the nanocrystals is much lower than that of the amorphous matrix, consistent with what is expected for a crystalline solid solution without barriers (such as grain boundaries) to dislocation motion.

The different mechanisms of hardening and softening in [am + fcc-Al] mixtures lead to different property dependences on crystallized volume fraction (represented by $F)$. With thermally induced crystallization the hardness rises with increasing $F$ at first weakly and then more strongly [40]. With mechanically induced crystallization, the hardness falls almost linearly with $F$ (Fig. 6c).

\subsection{Plasticity of amorphous/ $\alpha$-Al nanophase composites}

The mechanically induced crystallization of $84 \mathrm{Al}$ can be compared with thermally induced crystallization of the similar multicomponent $\mathrm{Al}_{85} \mathrm{Y}_{8} \mathrm{Ni}_{5} \mathrm{Co}_{1} \mathrm{Fe}_{0.5} \mathrm{Pd}_{0.5}$ amorphous alloy studied earlier [11]. The development of similar [am + fcc-Al] mixtures in these cases leads, respectively, to softening and hardening. Comparing the bending ductility, the annealed ribbons, even though they have higher volume fraction of fcc-Al, are very brittle, in contrast to the cold-rolled 
ribbons (Fig. 8).

This marked difference can be attributed to four factors. (1) the physical properties of amorphous alloys are affected by structural relaxation and rejuvenation. Structural relaxation leads to more stable atomic configurations accompanied by a decrease in internal energy (enthalpy relaxation), an increase in hardness, and embrittlement. Rejuvenation is the structural excitation of the amorphous phase, accompanied by an increase in enthalpy and free volume, and is thus the inverse of annealing-induced relaxation $[48,49]$. The amorphous matrix after annealing has undergone structural relaxation, known to favor embrittlement, whereas cold-rolling oppositely induces rejuvenation with consequent softening and ductilization. (2) on annealing, solute partitioning into the residual amorphous matrix can take its composition into a range where the alloy is intrinsically brittle, an effect that cannot arise in polymorphic crystallization induced by cold-rolling. (3) the fcc-Al/amorphous interface in cold-rolled $84 \mathrm{Al}$ is not solute-enriched, making the interface easier to deform and less brittle than it would be otherwise. (4) the absence of solute enrichment at the fcc-Al/amorphous interface may facilitate the generation and annihilation of dislocations that glide through the fcc-Al nanocrystals during cold-rolling.

Other families of amorphous alloys can undergo eutectic-like crystallization on annealing, where the formation of a multicomponent compound is associated with embrittlement of the partially crystalline alloy. For these, as for the Al-based alloys in the present work, cold deformation may be an attractive novel processing route to suppress compound formation and to obtain useful ductile amorphous-nanocrystalline mixtures.

\subsection{Failure to achieve work hardening}

The greatest obstacle, often noted, to wider exploitation of the desirable mechanical properties of bulk metallic glasses is the work-softening that leads to the concentration of flow in shear bands, and to catastrophic failure (effectively zero 
ductility) in tension. That (i) nanocrystallization can be induced by mechanical deformation of Al-based amorphous alloys [23], and (ii) that nanocrystallization on annealing the same alloys gives hardening [16,39], raised hopes that nanocrystallization could be a mechanism to induce work-hardening in these alloys, with consequent suppression of shear-banding. The present results explain why the ultimate aim of work-hardening is still not realized: nanocrystallization induced by deformation can lead to softening (Fig. 6) rather than hardening.

\section{Conclusions}

The effects of cold-rolling, near to LNT $(77 \mathrm{~K})$ or at RT, have been studied for two Al-based amorphous alloys with different thermal stabilities: $\mathrm{Al}_{90} \mathrm{Y}_{10}$ (at.\%) (90Al) which on heating shows crystallization onset at $485 \mathrm{~K}$, and $\mathrm{Al}_{84} \mathrm{Y}_{8.5} \mathrm{Ni}_{4} \mathrm{Co}_{2} \mathrm{Pd}_{1} \mathrm{Fe}_{0.5}$ (84Al) which shows the onset at $584 \mathrm{~K}$. Cold-rolling at LNT or RT in both $90 \mathrm{Al}$ and $84 \mathrm{Al}$ induces similar levels of partial nanocrystallization (despite the much greater thermal stability of the latter), giving an [am $+\mathrm{fcc}-\mathrm{Al}]$ phase mixture. The nanocrystallization leads to softening (by up to 34\%); this is the first report of this phenomenon, which is in marked contrast to the hardening (of similar magnitude) that results from thermally induced nanocrystallization. Annealing of $90 \mathrm{Al}$ gives a first crystallization step to an [am + fcc-Al] mixture similar to that given by cold-rolling. Annealing of $84 \mathrm{Al}$ gives in contrast an $[\mathrm{am}+\mathrm{fcc}-\mathrm{Al}+$ compound] mixture, where the formation of the compound, cubic $\mathrm{Al}_{x} \mathrm{M}_{y}(\mathrm{M}=\mathrm{Y}, \mathrm{Fe}$, $\mathrm{Co}, \mathrm{Ni}, \mathrm{Pd})$, is accompanied by extreme embrittlement.

Atom-probe field-ion microscopy of cold-rolled 84Al shows that the formation of fcc-Al nanocrystals is polymorphic (without solute partitioning), and it is inferred that the rolling-induced crystallization is polymorphic in $90 \mathrm{Al}$ also. This finding of unexpected polymorphic crystallization of amorphous alloys to a solid-solution phase is in contrast to the primary crystallization of fcc- $\mathrm{Al}$ (with solute partitioning) seen in annealed Al-based amorphous alloys.

The ability to achieve similar [am + fcc-Al] mixtures with and without solute 
partitioning leads to improved understanding of the property changes accompanying nanocrystallization. The hardening found on annealing is now clearly due to solute enrichment in the residual amorphous matrix, with the relatively soft nanocrystals having a ductilizing effect. On cold-rolling, without solute partitioning, otherwise similar nanocrystallization leads to overall softening, and good bending ductility is retained. Cold-rolling also delays embrittlement on subsequent annealing.

Polymorphic crystallization to fcc-Al with extended solid solubility may limit the degree of rejuvenation that can be achieved in deformed amorphous $\mathrm{Al}$ alloys. But it is useful in extending the composition and temperature ranges of the [am $+\mathrm{fcc}-\mathrm{Al}]$ mixture central to the development of high-solute Al-based alloys as structural materials.

\section{Acknowledgements}

The authors are grateful for supporting research funds from the Recruitment Program of Global Experts “1000 Talents Plan” (WQ20121200052), a Grant-in-Aid of MEXT (26630299) in Japan, the Deanship of Scientific Research (DSR), King Abdulaziz University, Jeddah, Saudi Arabia (1-1-435/HiCi) and the Ministry of Education and Science of the Russian Federation in the framework of the program aimed to increase the competitiveness of the National University of Science and Technology, "MISiS" (No. K1-2015-026). ALG acknowledges support from the European Research Council under the European Union's Horizon 2020 research and innovation programme (grant ERC-2015-AdG-695487: ExtendGlass).

\section{References}

[1] A. Inoue, H.M. Kimura, T. Masumoto, A.P. Tsai, Y. Bizen, Al-Ge-(Cr or Mn) and $\mathrm{Al}-\mathrm{Si}-(\mathrm{Cr}$ or $\mathrm{Mn})$ quasicrystals with high metalloid concentration prepared by rapid quenching, J. Mater. Sci. Lett. 6 (1987) 771-774.

[2] A. Inoue, M. Yamamoto, H.M. Kimura, T. Masumoto, Ductile aluminium-base amorphous alloys with two separate phases, J. Mater. Sci. Lett. 6 (1987) 194-196. 
[3] A. Inoue, K. Ohtera, A.P. Tsai, T. Masumoto, Aluminum-based amorphous alloys with tensile strength above $980 \mathrm{MPa}\left(100 \mathrm{~kg} / \mathrm{mm}^{2}\right)$, Jpn J. Appl. Phys. 27 (1988) L479-L482.

[4] Y. He, S.J. Poon, G.J. Shiflet, Synthesis and properties of metallic glasses that contain aluminum, Science 241 (1988) 1640-1642.

[5] A. Inoue, N. Matsumoto, T. Masumoto, Al-Ni-Y-Co amorphous alloys with high mechanical strengths, wide supercooled liquid region and large glass-forming capacity, Mater. Trans. JIM 31 (1990) 493-500.

[6] A. Inoue, S. Sobu, D.V. Louzguine, H. Kimura, K. Sasamori, Ultrahigh strength Al-based amorphous alloys containing Sc, J. Mater. Res. 19 (2004) 1539-1543.

[7] J.C. Foley, D.R. Allen, J.H. Perepezko, Analysis of nanocrystal development in Al-Y-Fe and Al-Sm glasses, Scripta Mater. 35 (1996) 655-660.

[8] D.R. Allen, J.C. Foley, J.H. Perepezko, Nanocrystal development during primary crystallization of amorphous alloys, Acta Mater. 46 (1998) 431-440.

[9] T. Gloriant, A.L. Greer, Al-based nanocrystalline composites by rapid solidification of Al-Ni-Sm alloys, Nanostruct. Mater. 10 (1998) 389-396.

[10] J.H. Perepezko, R.J. Hebert, R.I. Wu, G. Wilde, Primary crystallization in amorphous Al-based alloys, J. Non-Cryst. Solids 317 (2003) 52-61.

[11] F.F. Han, A. Inoue, Y. Han, F.L. Kong, S.L. Zhu, E. Shalaan, F. Al-Marzouki, A.L. Greer, Novel heating-induced reversion during crystallization of Al-based glassy alloys, Sci. Rep. 7 (2017) 46113.

[12] D.V. Louzguine-Luzgin, A. Inoue, Comparative study of the effect of cold rolling on the structure of Al-RE-Ni-Co (RE=rare-earth metals) amorphous and glassy alloys, J. Non-Cryst. Solids 352 (2006) 3903-3909.

[13] R.J. Hebert, J.H. Perepezko, Effect of cold-rolling on the crystallization behavior of amorphous $\mathrm{Al}_{88} \mathrm{Y}_{7} \mathrm{Fe}_{5}$ alloy, Mater. Sci. Eng. A 375-377 (2004) $728-732$.

[14] J.Q. Guo, K. Ohtera, K. Kita, Crystallization behavior of amorphous $\mathrm{Al}_{90} \mathrm{Y}_{10}$ and $\mathrm{Al}_{88} \mathrm{Y}_{12}$ alloys, Mater. Lett. 24 (1995) 127-132.

[15] E. Pershina, D. Matveev, G. Abrosimova, A. Aronin, E. Pershina, D. Matveev, G. Abrosimova, A. Aronin, Formation of nanocrystals in an amorphous $\mathrm{Al}_{90} \mathrm{Y}_{10}$ alloy, Mater. Charact. 133 (2017) 87-93.

[16] Y.H. Kim, A. Inoue, T. Masumoto, Ultrahigh tensile strengths of $\mathrm{Al}_{88} \mathrm{Y}_{2} \mathrm{Ni}_{9} \mathrm{M}_{1}$ $(\mathrm{M}=\mathrm{Mn}$ or $\mathrm{Fe}$ ) amorphous alloys containing finely dispersed fcc-Al particles, Mater. Trans. JIM 31 (1990) 747-749.

[17] H. Chen, Y. He, G.J. Shiflet, S.J. Poon, Deformation-induced nanocrystal formation in shear bands of amorphous alloys, Nature 367 (1994) 541-543.

[18] M.C. Gao, R.E. Hackenberg, G.J. Shiflet, Deformation-induced nanocrystal precipitation in Al-base metallic glasses, Mater. Trans. 42 (2001) 1741-1747.

[19] G. Wilde, H. Sieber, J.H. Perepezko, Glass formation versus nanocrystallization in an $\mathrm{Al}_{92} \mathrm{Sm}_{8}$ alloy, Scripta Mater. 40 (1999) 779-783.

[20] F.X. Zhang, W.K. Wang, Amorphization of Al-Cu-Fe quasicrystalline alloys by mechanical milling, J Alloy Compd, 240 (1996) 256-260.

[21] I. Manna, P.P. Chattopadhyay, F. Banhart, H.J. Fecht, Development of amorphous 
and nanocrystalline $\mathrm{Al}_{65} \mathrm{Cu}_{35-\mathrm{x}} \mathrm{Zr}_{\mathrm{x}}$ alloys by mechanical alloying, Mater. Sci. Eng. A 379(1-2) (2004) 360-365.

[22] E. Pershina, G. Abrosimova, A. Aronin, D. Matveev, V. Tkatch, Crystallization features in $\mathrm{Al}_{90} \mathrm{Y}_{10}$ amorphous alloy under a various external influence, Mater. Lett. 134(7) (2014) 60-63.

[23] A. Inoue, Amorphous, nanoquasicrystalline and nanocrystalline alloys in Al-based systems, Prog. Mater. Sci. 43 (1998) 365-520.

[24] N. Bassim, C. Kiminami, M. Kaufman, Phases formed during crystallization of amorphous $\mathrm{Al}_{84} \mathrm{Y}_{9} \mathrm{Ni}_{5} \mathrm{Co}_{2}$ alloy, J Non-cryst Solids 273(1) (2000) 271-276.

[25] H. Bei, S. Xie, E.P. George, Softening caused by profuse shear banding in a bulk metallic glass, Phys. Rev. Lett. 96 (2006) 105503.

[26] Y. Sun, A. Concustell, A.L. Greer, Thermomechanical processing of metallic glasses: extending the range of the glassy state, Nat. Rev. Mater. 1 (2016) 16039.

[27] T. Masumoto, H. Kimura, A. Inoue, Y. Waseda, Structural stability of amorphous metals, Mater. Sci. Eng. 23 (1976) 141-144.

[28] A.L. Greer, Metallic Glasses, in: D.E. Laughlin, K. Hono (Eds.) Physical Metallurgy, Elsevier, Oxford, 2014, pp. 305-385.

[29] T. Egami, W. Guo, P.D. Rack, T. Nagase, Irradiation resistance of multicomponent alloys, Metall. Mater. Trans. A 45A (2014) 180-183.

[30] A.L. Greer, Y.Q. Cheng, E. Ma, Shear bands in metallic glasses, Mater. Sci. Eng. R 74 (2013) 71-132.

[31] A.A. Csontos, G.J. Shiflet, Formation and chemistry of nanocrystalline phases formed during deformation in aluminum-rich metallic glasses, Nanostruct. Mater. 9 (1997) 281-289.

[32] P.M. Smith, M.J. Aziz, Solute trapping in aluminum alloys, Acta Metall. Mater. 42 (1994) 3515-3525.

[33] C.C. Wang, Y.W. Mao, Z.W. Shan, M. Dao, J. Li, J. Sun, E. Ma, S. Suresh, Real-time, high-resolution study of nanocrystallization and fatigue cracking in a cyclically strained metallic glass, PNAS, 110 (2013) 19725-19730.

[34] Y.W. Mao, J. Li,Y.C. Lo, X.F. Qian, E. Ma, Stress-driven crystallization via shear-diffusion transformations in a metallic glass at very low temperatures, Phys. Rev. B 91 (2015) 214103.

[35] A.L. Greer, Y.H. Sun, Stored energy in metallic glasses due to strains within the elastic limit, Philos. Mag. 96 (2016) 1643-1663.

[36] Y.Q. Cheng, H.W. Sheng, E. Ma, Relationship between structure, dynamics, and mechanical properties in metallic glass-forming alloys, Phys. Rev. B 78 (2008) 014207.

[37] S.-W. Lee, M.-Y. Huh, E. Fleury, J.-C. Lee, Crystallization-induced plasticity of $\mathrm{Cu}-\mathrm{Zr}$ containing bulk amorphous alloys, Acta Mater. 54 (2006) 349-355.

[38] A. Caron, A. Kawashima, H.-J. Fecht, D.V. Louzguine-Luzgin, A. Inoue, On the anelasticity and strain induced structural changes in a Zr-based bulk metallic glass, Appl. Phys. Lett. 99 (2011) 171907. 
[39] H. Chen, Y. He, G.J. Shiflet, S.J. Poon, Mechanical properties of partially crystallized aluminum based metallic glasses, Scripta Metall. 25 (1991) 1421-1424.

[40] K. Hono, Y. Zhang, A.P. Tsai, A. Inoue, T. Sakurai, Solute partitioning in partially crystallized Al-Ni-Ce(-Cu) metallic glasses, Scripta Metall. Mater. 32 (1995) 191-196.

[41] Y.H. Kim, A. Inoue, T. Masumoto, Increase in mechanical strength of Al-Ni-Y amorphous alloys by dispersion of nanoscale fcc-Al particles, Mater. Trans. JIM 32 (1991) 331-338.

[42] Y.H. Kim, K. Hiraga, A. Inoue, T. Masumoto, H.H. Jo, Crystallization and high mechanical strength of Al-based amorphous alloys, Mater. Trans. JIM 35 (1994) 293-302.

[43] M. Bletry, P. Guyot, Y. Brechet, J.J. Blandin, J.L. Soubeyroux, Homogeneous deformation of $\mathrm{Zr}-\mathrm{Ti}-\mathrm{Al}-\mathrm{Cu}-\mathrm{Ni}$ bulk metallic glasses, Intermet. 12 (2004) 1051-1055.

[44] Z.C. Zhong, X.Y. Jiang, A.L. Greer, Nanocrystallization in Al-based amorphous alloys, Philos. Mag. B 76 (1997) 505-510.

[45] Z.C. Zhong, X.Y. Jiang, A.L. Greer, Microstructure and hardening of Al-based nanophase composites, Mater. Sci. Eng. A 226-228 (1997) 531-535.

[46] J.A. del Valle, F. Carreño, O.A. Ruano, Influence of texture and grain size on work hardening and ductility in magnesium-based alloys processed by ECAP and rolling, Acta Mater. 54 (2006) 4247-4259.

[47] L. Kurmanaeva, Yu. Ivanisenko, J. Markmann, K. Yang, H.-J. Fecht, J. Weissmüller, Work hardening and inherent plastic instability of nanocrystalline metals, Phys. Status Solidi RRL 4 (2010) 130-132.

[48] T. Egami, Structural relaxation in metallic glasses, Ann. NY Acad. Sci. 371(1) (1981) 238-251.

[49] S.V. Ketov, Y.H. Sun, S. Nachum, Z. Lu, A. Checchi, A.R. Beraldin, H.Y. Bai, W.H. Wang, D.V. Louzguine-Luzgin, M.A. Carpenter, A.L. Greer, Rejuvenation of metallic glasses by non-affine thermal strain, Nature 524 (2015) 200-203. 


\section{Figure Captions}

Fig. 1. Transmission electron microscopy of amorphous alloy ribbons rolled near to LNT (77 K). Bright-field TEM image (a), selected-area electron diffraction pattern (b) and HRTEM image (c) of the 90Al amorphous alloy cold-rolled to $75 \%$ reduction in thickness. Bright-field TEM image (d), selected-area electron diffraction pattern (e) and HRTEM image (f) of the 84Al amorphous alloy cold-rolled to $86 \%$ reduction in thickness.

Fig. 2. Atom-probe field-ion microscopy of cold-rolled 84Al amorphous alloy. The profiles show the change in content of the constituent $\mathrm{Al}, \mathrm{Y}, \mathrm{Ni}, \mathrm{Co}, \mathrm{Pd}$ and $\mathrm{Fe}$ elements with distance for the 84Al amorphous alloy rolled at LNT to reduction in thickness $R=86 \%$. The profiles are moderately flat apart from the transient surface effect seen for depths less than $\sim 15 \mathrm{~nm}$.

Fig. 3. Atom-probe field-ion microscopy of cold-rolled 84Al amorphous alloy. Elemental concentration maps of Al, Y, Ni, Co, Pd and Fe elements for the 84Al alloy rolled at LNT to $R=86 \%$. The tip has a length of $\sim 300 \mathrm{~nm}$ and a diameter of $\sim 150$ nm.

Fig. 4. Differential scanning calorimetry of as-spun and cold-rolled amorphous alloy ribbons. DSC curves (heating rate $0.67 \mathrm{~K} / \mathrm{s}$ ) of (a) $90 \mathrm{Al}$ and (b) $84 \mathrm{Al}$ ribbons, rolled at LNT to the indicated thicknesses. (c) Peak temperatures of the first and second exotherms as a function of reduction in thickness by rolling $90 \mathrm{Al}$ or $84 \mathrm{Al}$ ribbons at LNT. (d) Fractional reduction $F$ in the total heat of transformation, from peak areas in DSC curves, as a function of reduction in thickness by rolling $90 \mathrm{Al}$ or $84 \mathrm{Al}$ ribbons at LNT or RT.

Fig. 5. X-ray diffractometry of annealed amorphous alloy ribbons. Diffraction patterns (CuKa radiation) of the $90 \mathrm{Al}$ and $84 \mathrm{Al}$ amorphous alloys annealed for $600 \mathrm{~s}$ at a temperature just above the first exothermic peak.

Fig. 6. Vickers microhardness $H_{\mathrm{v}}$ of as-spun and cold-rolled amorphous alloy ribbons. The change in $H_{\mathrm{v}}$ with reduction in thickness $(R)$ for the cold-rolled (a) $90 \mathrm{Al}$ and (b) $84 \mathrm{Al}$ amorphous alloys. (c) The hardness of $90 \mathrm{Al}$ and $84 \mathrm{Al}$ ribbons relative to their hardness in the as-spun state as a function of fractional reduction $F$ in the total heat of transformation after cold-rolling. 
Fig. 7. Vickers microhardness $H_{\mathrm{v}}$ of ribbons cold-rolled at LNT (to $22 \mu \mathrm{m} R=37 \%$, or to $10 \mu \mathrm{m} R=71 \%$ ) and subsequently annealed. The $H_{\mathrm{v}}$ values of the cold-rolled (a) $90 \mathrm{Al}$ and (b) $84 \mathrm{Al}$ amorphous alloys are shown for annealing times at $450 \mathrm{~K}$ $\left(T_{\mathrm{x} 1}-35 \mathrm{~K}\right)$ and $525 \mathrm{~K}\left(T_{\mathrm{x} 1}-60 \mathrm{~K}\right)$, respectively. The data for the as-spun amorphous alloys are also shown for comparison.

Fig. 8. Plasticity of cold-rolled amorphous alloy ribbons. (a) Cold-rolled 84Al ribbons show good bending ductility. SEM images of the ribbon surface in the bent region for (b) an $84 \mathrm{Al}$ ribbon and (c) a $90 \mathrm{Al}$ ribbon cold-rolled to $R \approx 60 \%$.

Fig. 9. The relative free energies of the phases relevant for the first-stage crystallization of $\mathrm{Al}_{84} \mathrm{Y}_{8.5} \mathrm{Ni}_{4} \mathrm{Co}_{2} \mathrm{Pd}_{1} \mathrm{Fe}_{0.5}$ amorphous alloy. On annealing at $584 \mathrm{~K}$ (at the onset temperature $T_{\mathrm{x} 1}$ for crystallization on heating), the amorphous alloy undergoes (arrow 1) eutectic-like crystallization to $\alpha$-Al of reduced solute content and the cubic compound $\mathrm{Al}_{x} \mathrm{M}_{y}(\mathrm{M}=\mathrm{Y}, \mathrm{Fe}, \mathrm{Co}, \mathrm{Ni}, \mathrm{Pd}) . \quad$ At RT and at LNT, the Gibbs free energy of the amorphous alloy is higher relative to those of the crystalline phases and it can undergo polymorphic crystallization (arrow 2 ) to $\alpha$-Al with extended solid solubility. 


\section{FIGURES}
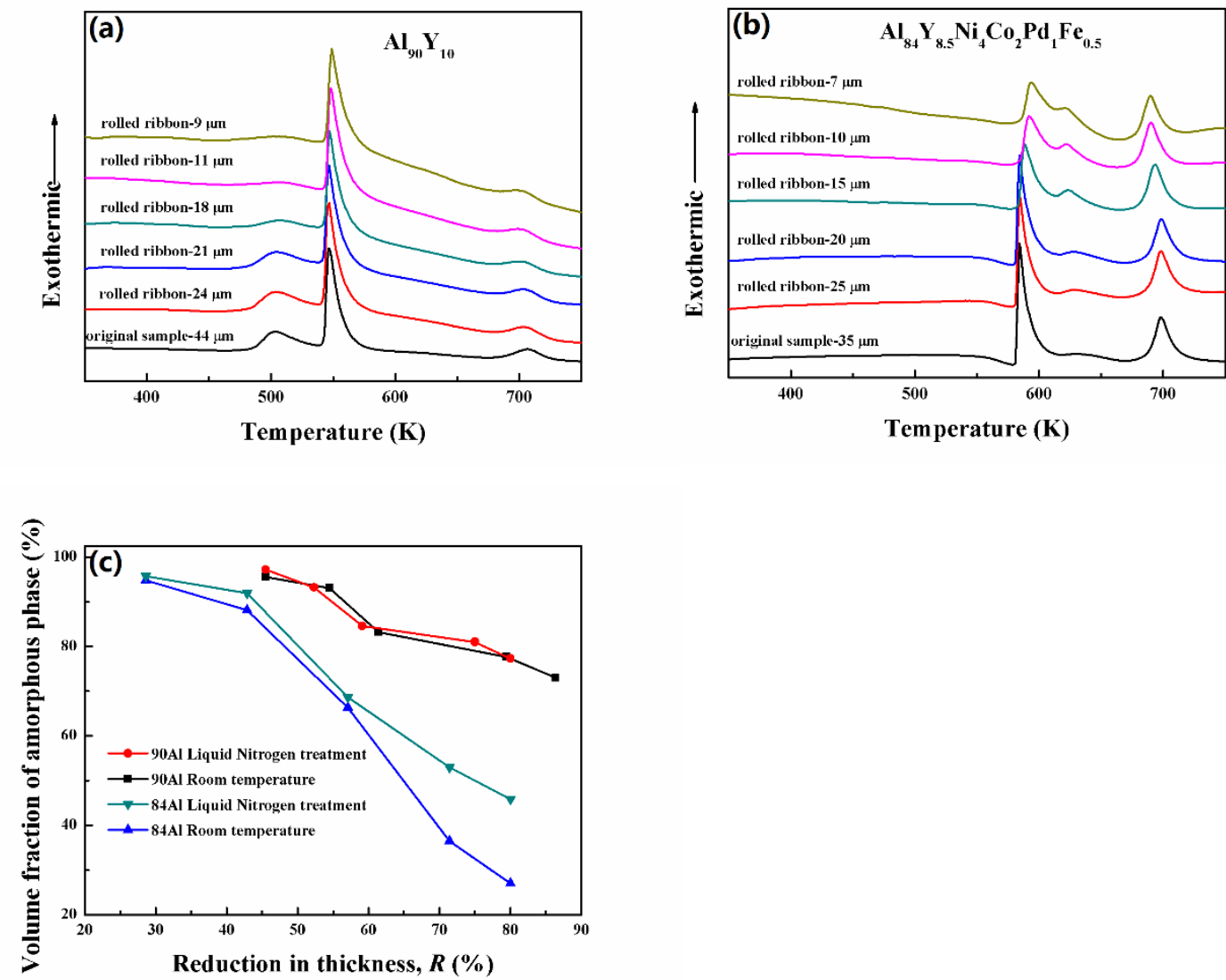

Figure 1. DSC curves (heating rate $0.67 \mathrm{~K} / \mathrm{s}$ ) of (a) $90 \mathrm{Al}$ and (b) $84 \mathrm{Al}$ amorphous alloy ribbons, rolled at LNT to the indicated thicknesses. (c) Volume fraction of the residual amorphous phase, estimated from peak areas in DSC curves, as a function of reduction in thickness by rolling $90 \mathrm{Al}$ or $84 \mathrm{Al}$ ribbons at LNT or RT. 


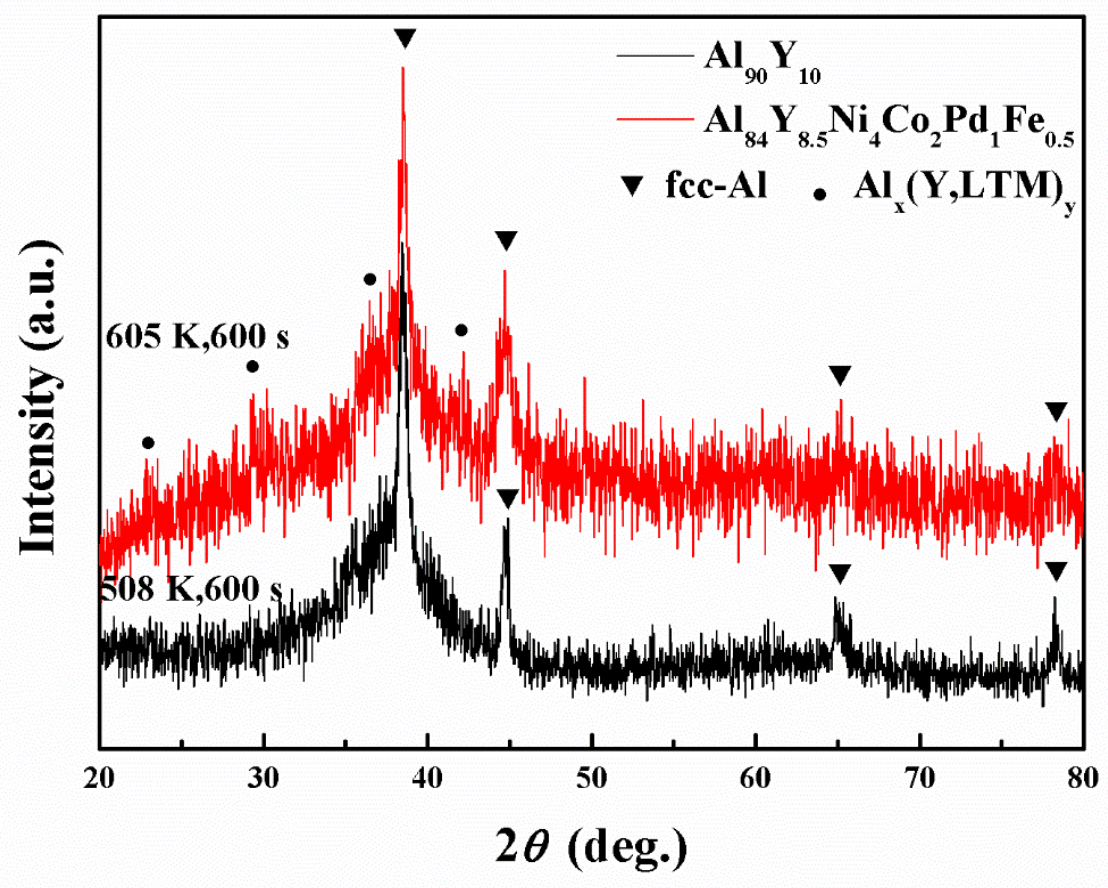

Figure 2. X-ray diffraction patterns $(\mathrm{Cu} \mathrm{K \alpha}$ radiation) of the $90 \mathrm{Al}$ and $84 \mathrm{Al}$ amorphous alloys annealed for $600 \mathrm{~s}$ at a temperature just above the first exothermic peak. 


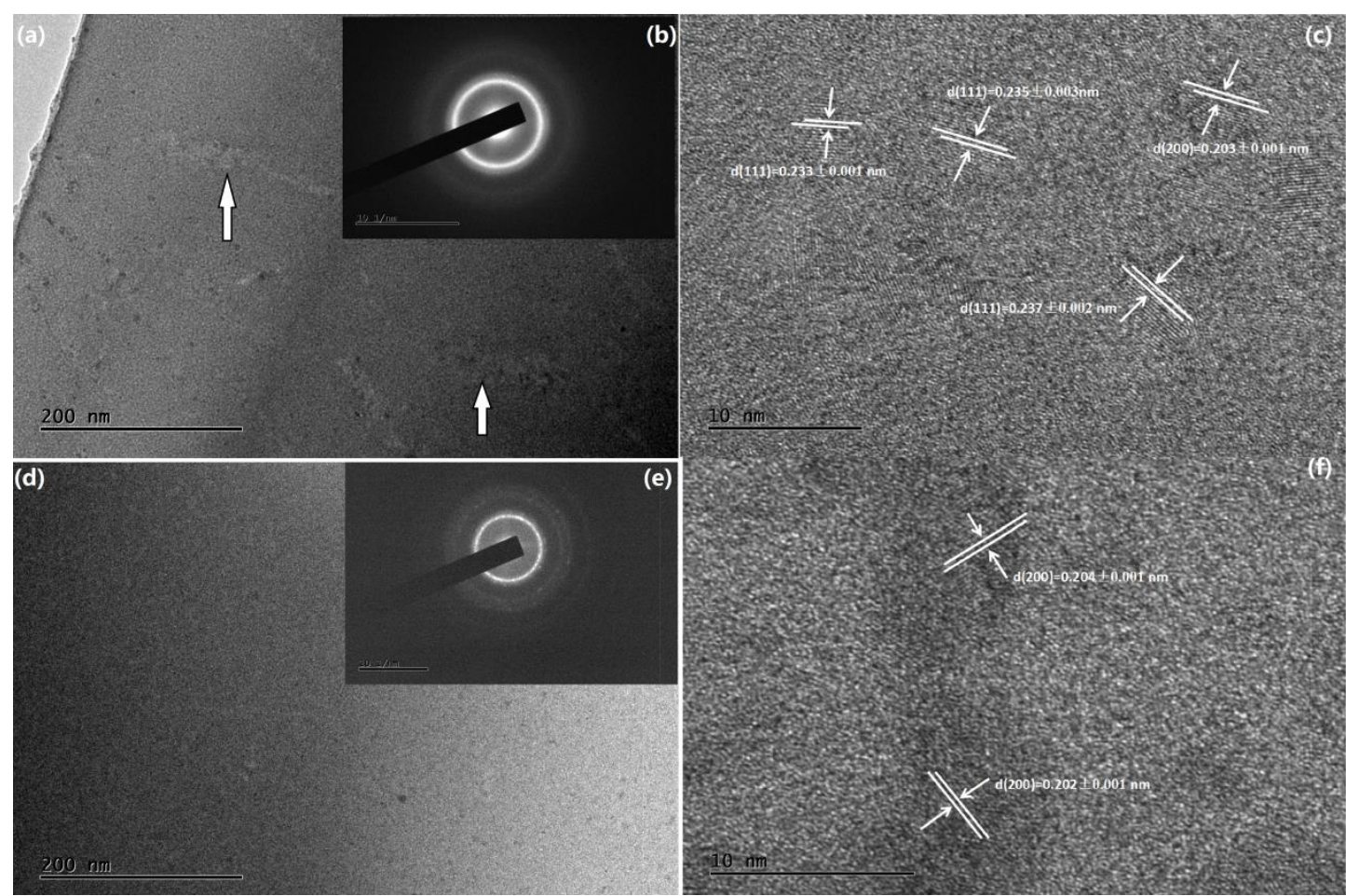

Figure 3. Bright-field TEM image (a), selected-area electron diffraction pattern (b) and HRTEM image (c) of the $90 \mathrm{Al}$ amorphous alloy cold-rolled to $75 \%$ reduction in thickness. Bright-field TEM image (d), selected-area electron diffraction pattern (e) and HRTEM image (f) of the $84 \mathrm{Al}$ amorphous alloy cold-rolled to $86 \%$ reduction in thickness. 


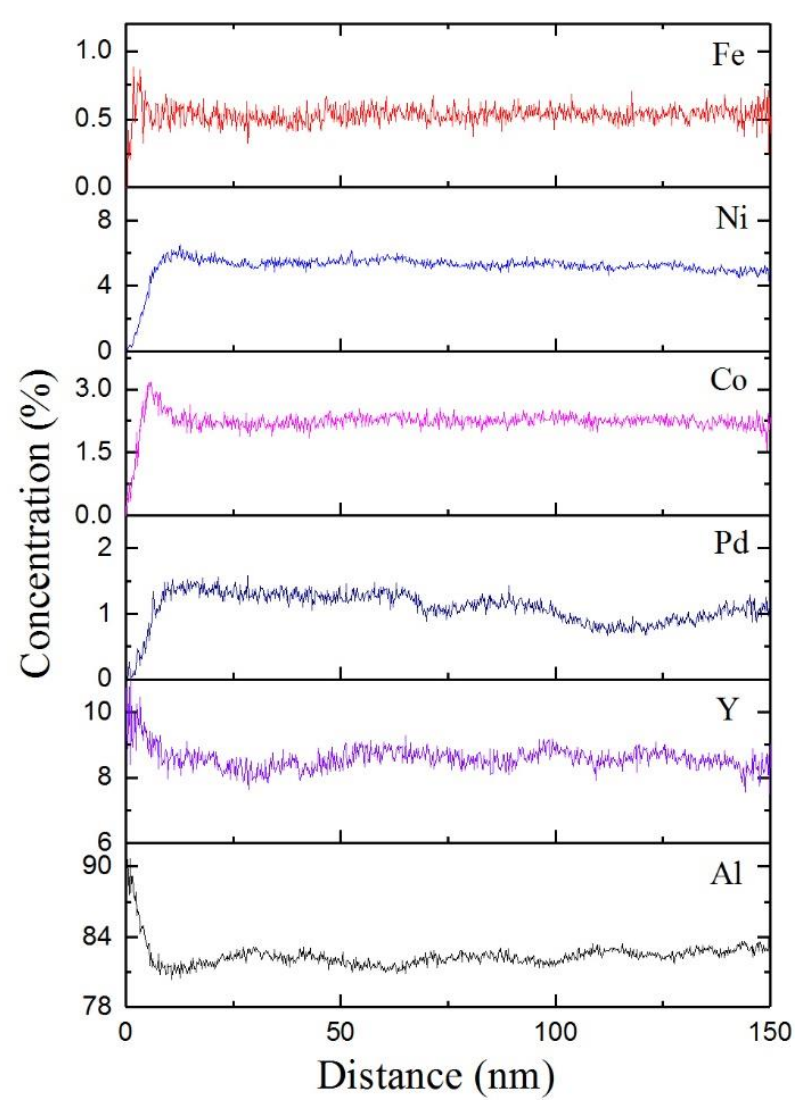

Figure 4. APFIM profiles showing the change in content of the constituent $\mathrm{Al}, \mathrm{Y}, \mathrm{Ni}$, $\mathrm{Co}, \mathrm{Pd}$ and $\mathrm{Fe}$ elements with distance for the 84Al amorphous alloy rolled at LNT to $R=86 \%$. The profiles are moderately flat apart from the transient surface effect seen for depths less than $\sim 15 \mathrm{~nm}$. 

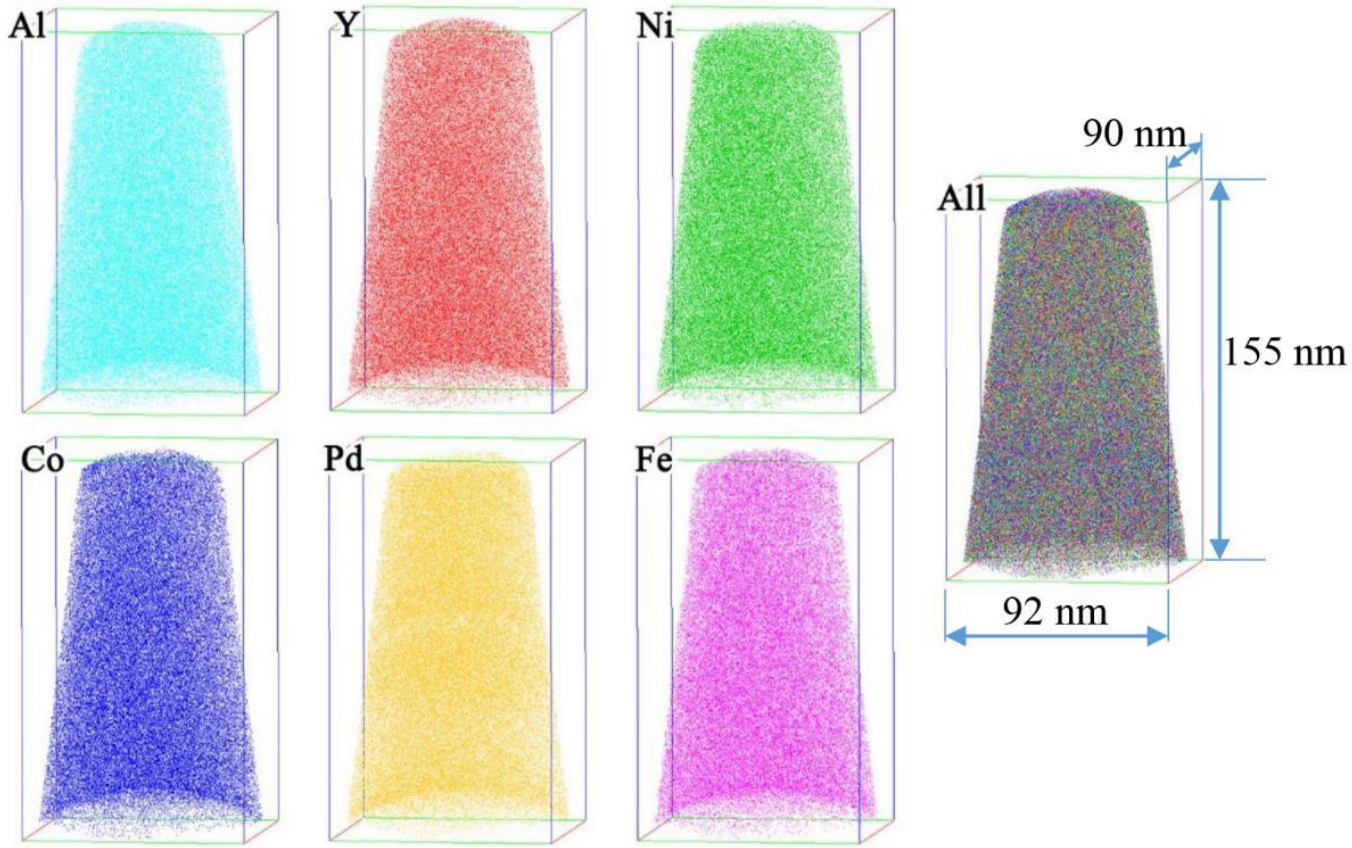

Figure 5. APFIM elemental concentration maps of $\mathrm{Al}, \mathrm{Y}, \mathrm{Ni}, \mathrm{Co}, \mathrm{Pd}$ and $\mathrm{Fe}$ elements for the 84Al alloy rolled at LNT to $R=86 \%$. The tip has a length of $\sim 300$ $\mathrm{nm}$ and a diameter of $\sim 150 \mathrm{~nm}$. 

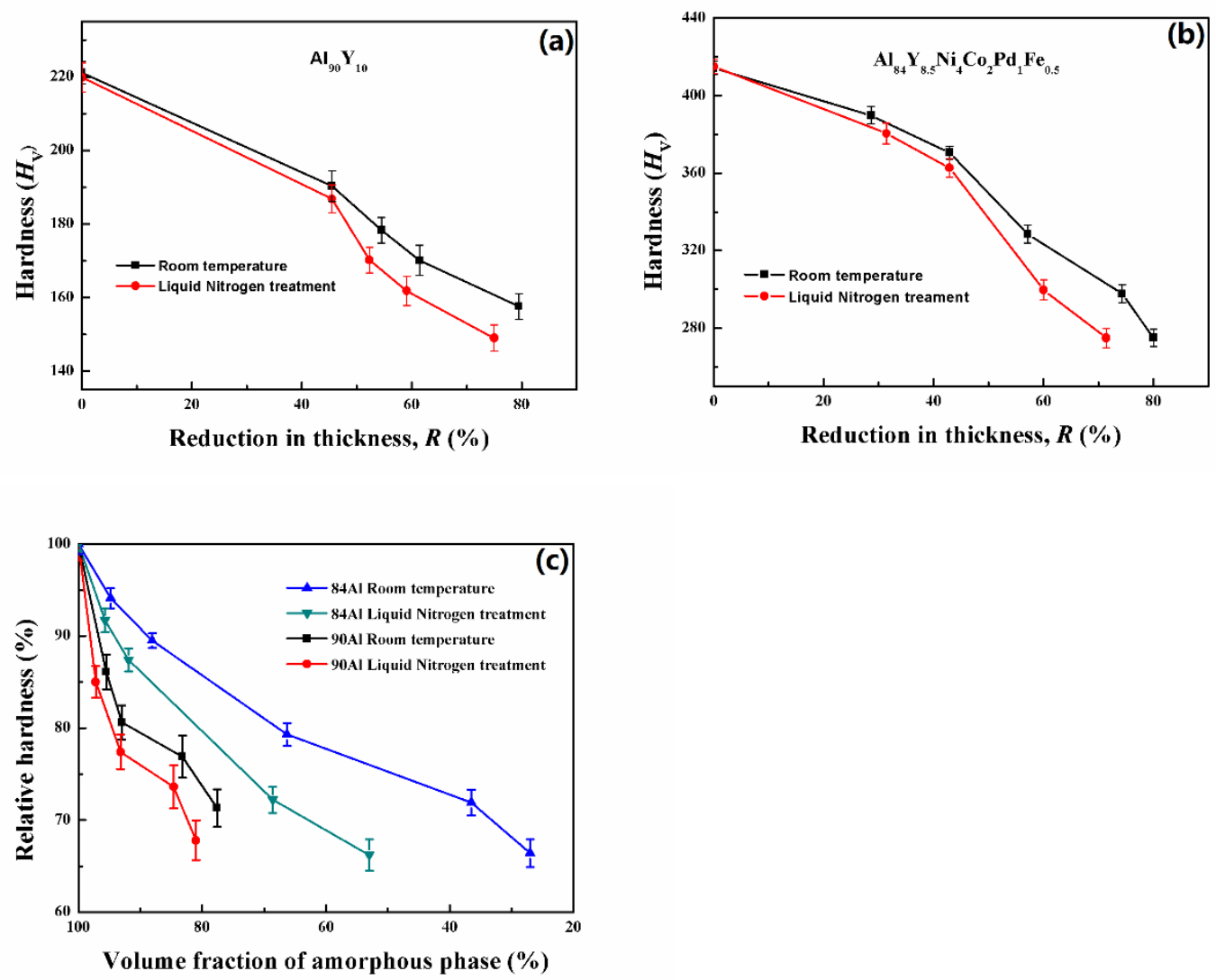

Figure 6. (a,b) The change in Vickers hardness with reduction in thickness $(R)$ for the cold-rolled 90Al and 84Al amorphous alloys. (c) The hardness of 90Al and 84Al ribbons relative to their hardness in the as-spun state as a function of the volume fraction of the residual amorphous phase after cold-rolling. 

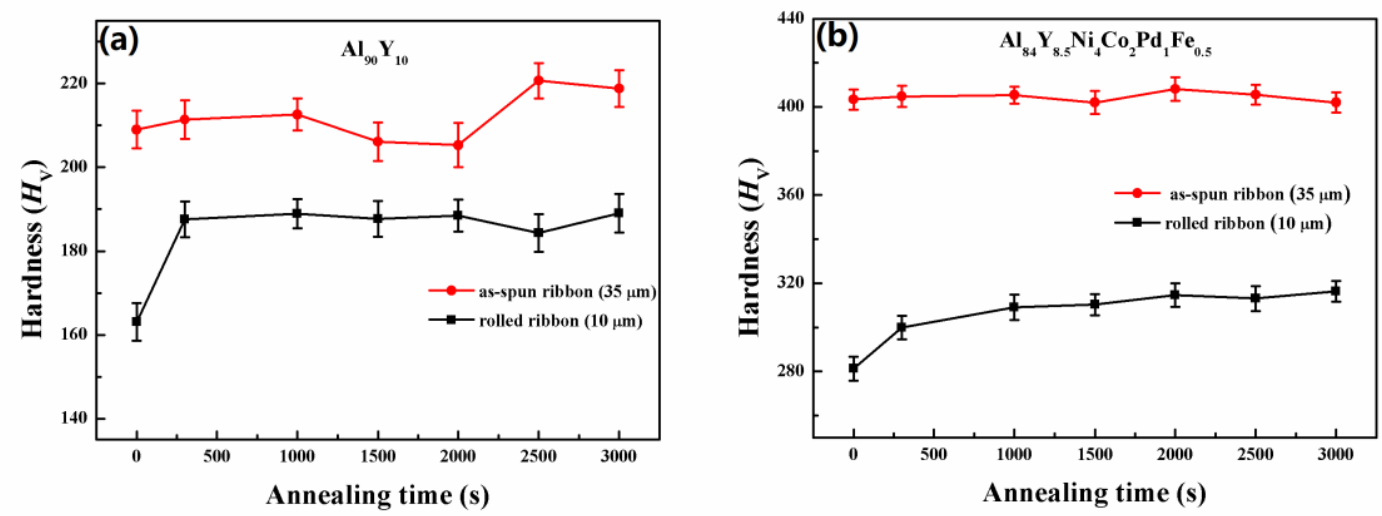

Figure 7. (a,b) Change in Vickers hardness of the cold rolled 90Al and 84Al amorphous alloys with annealing times at $450 \mathrm{~K}\left(T_{\mathrm{x} 1}-35 \mathrm{~K}\right)$ and $525 \mathrm{~K}\left(T_{\mathrm{x} 1}-60 \mathrm{~K}\right)$, respectively. The data for the as-spun amorphous alloys are also shown for comparison. The cold-rolling reduction in thickness is $70 \%$ for both alloys.

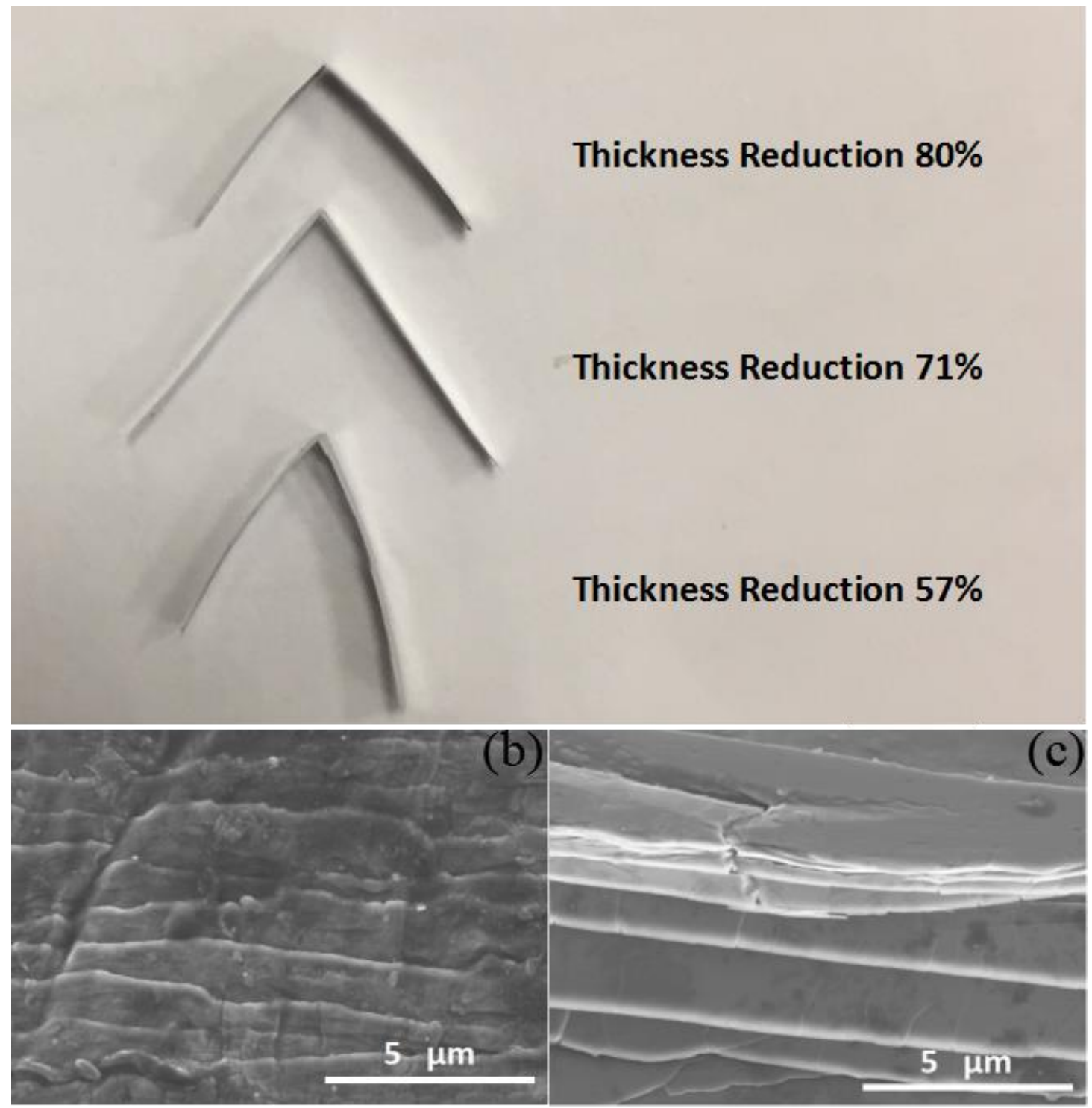


Figure 8. (a) Cold-rolled 84Al ribbons showing good bending ductility. SEM images of the ribbon surface in the bent region for (b) an 84Al ribbon and (c) a 90Al ribbons cold-rolled to $R \approx 60 \%$.

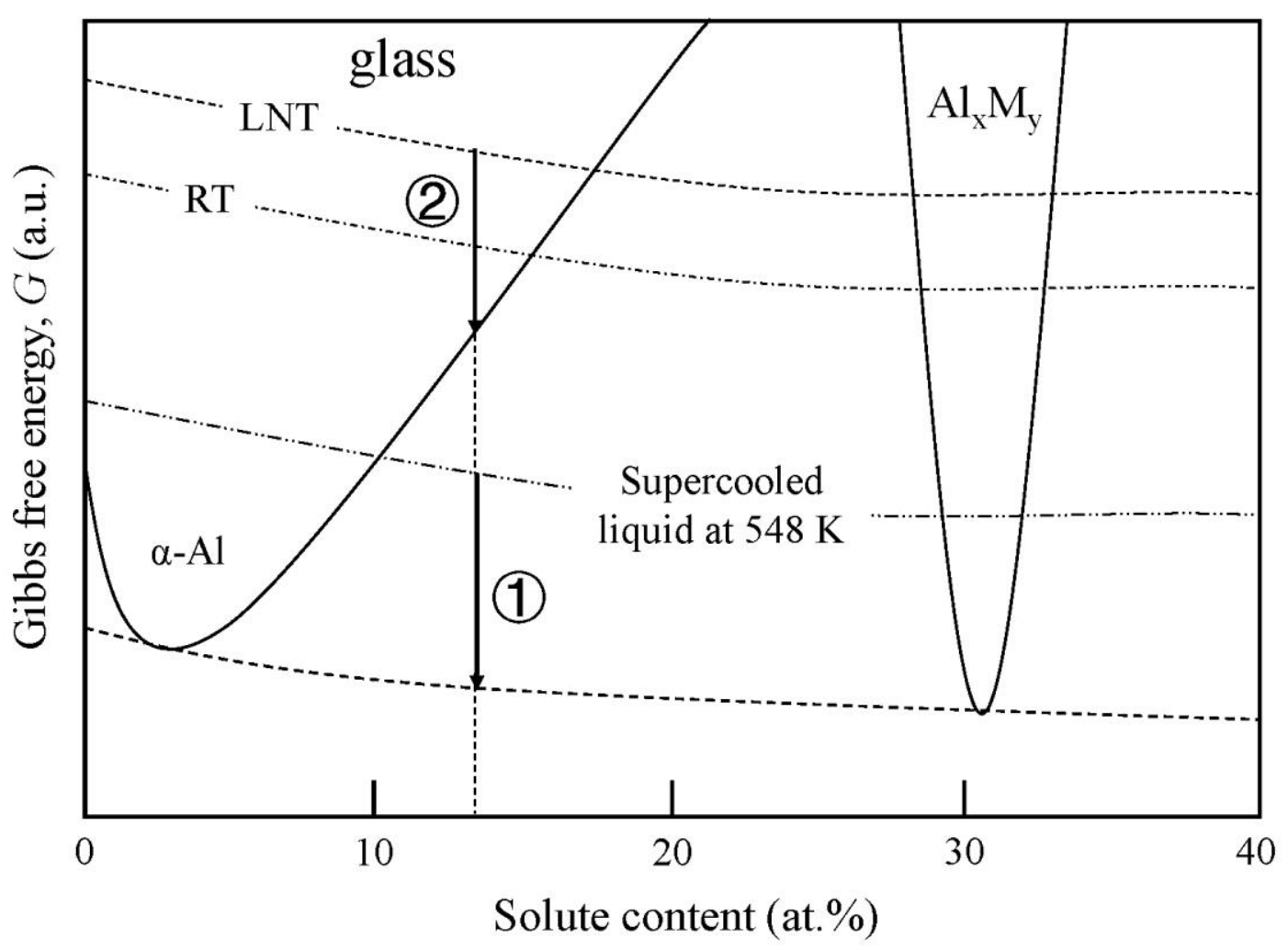

Figure 9. The relative free energies of the phases relevant for the first-stage crystallization of $\mathrm{Al}_{84} \mathrm{Y}_{8.5} \mathrm{Ni}_{4} \mathrm{Co}_{2} \mathrm{Pd}_{1} \mathrm{Fe}_{0.5}$ amorphous alloy. On annealing at $548 \mathrm{~K}$ (at the onset temperature $T_{\mathrm{x} 1}$ for crystallization on heating), the amorphous alloy undergoes (arrow 1) eutectic-like crystallization to $\alpha$-Al of reduced solute content and the cubic compound $\mathrm{Al}_{x} \mathrm{M}_{y}(\mathrm{M}=\mathrm{Y}, \mathrm{Fe}, \mathrm{Co}, \mathrm{Ni}, \mathrm{Pd})$. At RT and at LNT, the Gibbs free energy of the amorphous alloy is higher relative to those of the crystalline phases and it can undergo polymorphic crystallization (arrow 2 ) to $\alpha$-Al with extended solid solubility. 
Table 1. Structure and bending ductility of the 90Al and 84Al amorphous alloy ribbons subjected to low-temperature annealing, heating near to crystallization onset at $T_{\mathbf{x} 1}$ and cold rolling.

\begin{tabular}{|c|c|c|c|c|c|c|}
\hline \multirow{2}{*}{ - } & \multicolumn{2}{|c|}{ Low temperature annealing } & \multicolumn{2}{|c|}{ Heating just above $T_{\mathrm{x} 1}$ for $600 \mathrm{~s}$} & \multicolumn{2}{|c|}{ Cold rolling to $80 \%$ reduction in thickness } \\
\hline & Structure & Ductility & Structure & Ductility & Structure & Ductility \\
\hline $90 \mathrm{Al}$ & $\begin{array}{c}\mathrm{am} \rightarrow \mathrm{am}+\alpha-\mathrm{Al} \\
\left(T_{\mathrm{x} 1}-35 \mathrm{~K}\right), 2500 \mathrm{~s}\end{array}$ & Ductile & $\alpha-\mathrm{Al}+\mathrm{am}$ & Ductile & $\begin{array}{l}\alpha-\mathrm{Al} \text { (supersaturated } \\
\text { solid solution) }+\mathrm{am}\end{array}$ & Ductile \\
\hline $84 \mathrm{Al}$ & $\begin{array}{c}\mathrm{am} \\
\left(T_{\mathrm{x}}-60 \mathrm{~K}\right), 3000 \mathrm{~s}\end{array}$ & $\begin{array}{c}\text { Ductile } \rightarrow \text { Brittle } \\
\text { after } 700 \mathrm{~s}\end{array}$ & $\begin{array}{c}\alpha-\mathrm{Al}+\mathrm{Al}_{x}(\mathrm{Y}, \mathrm{LTM})_{y}+ \\
\mathrm{am}\end{array}$ & Brittle & $\begin{array}{l}\alpha-\mathrm{Al} \text { (supersaturated } \\
\text { solid solution) }+\mathrm{am}\end{array}$ & Ductile \\
\hline
\end{tabular}

